\title{
PRAÇA ERNESTO TOCHETTO: IMPORTÂNCIA DA SUA PRESERVAÇÃO HISTÓRICA E ASPECTOS DE SUA ARBORIZAÇÃO
}

\author{
Evanisa Fatima Reginato Quevedo Melo; Anicoli Romanini
}

(recebido em 30.07.2007 e aceito pra publicação em 20.03.2008)

\section{RESUMO}

A imagem da cidade não se traduz apenas nas vias, prédios e serviços, ela se diferencia por todo o repertório de sua memória. Assim, a integração das praças na malha urbana e sua apropriação pela comunidade são reflexos do grau de visibilidade imposto pelo entorno diretamente à praça e vice-versa, o qual é conseqüência direta das estruturas vegetais empregadas. Este trabalho, portanto, tem por objetivo fazer uma análise da Praça Ernesto Tochetto, em Passo Fundo/RS, originada em meados de 1963, em homenagem ao emérito educador Ernesto Tochetto, conta com sua imagem preservada até hoje na representação da sua sala de aula. A Praça Tochetto, com uma posição privilegiada se constitui em um espaço público multifuncional de grande importância no contexto urbano local. Os resultados do estudo apontam por melhoramento dos bancos, aumento de árvores com flores, iluminação e passeios, e conclui que a praça procura resgatar a memória de seus antepassados com suas características originais, mas esbarra no desinteresse dos usuários quanto a sua história. Por evocar o ambiente natural, a praça requer um tratamento paisagístico especial, para se tornar ainda mais um espaço agradável para contemplação, leitura, conversas com os amigos ou simplesmente o descanso.

Palavras-chave: Arborização Urbana, Praça, Espaço Público.

\footnotetext{
${ }^{1}$ Doutora, Professora Universidade de Passo Fundo, Passo Fundo, RS, evanisa@upf.br

2 Doutoranda do Programa de Pós-Graduação em Planejamento Urbano e Regional, Universidade Federal do Rio Grande do Sul, Porto Alegre, arquiteta anicoli@yahoo.com.br
} 


\title{
PLAZA ERNESTO TOCHETTO: IMPORTANCE IN URBAN ARBORIZATION AND HISTORICAL PRESERVATION
}

\begin{abstract}
The image of the city does not result only in roads, buildings and services, she difference in the entire repertoire of his memory. Thus, the integration of the urban squares and its ownership by the community are reflected in the degree of visibility imposed by the environment directly to the square and vice versa, which is a direct consequence of the structures plant employed. This study, therefore, aims to make an analysis of the Plaza Ernesto Tochetto in Passo Fundo / RS, originated in mid-1963, in honor of emeritus educator Ernesto Tochetto, has his image preserved today in the representation of your classroom . The Tochetto Square, with a privileged position, as is in a public space multifunctional of great importance in the city location. The results of the study show improvement by the banks, increase of trees with flowers, lighting and tours, and concludes that the square seeks redeem the memory of their ancestors with their original characteristics, but hampered in the disinterest from users about its history. By evoking the natural environment, the square calls for a special landscape, to become even more attractive to a space contemplation, reading, conversations with friends or simply to rest.
\end{abstract}

Key Words: Urban Arborization, Square, Public Space. 


\section{INTRODUÇÃO}

A arborização urbana, no Brasil, é considerado um tema recente, de evolução lenta e do qual as administrações públicas e a comunidade devem se envolver, cumprindo papéis distintos. Atualmente, em cidades onde ocorre o planejamento das arborizações, a preocupação é tornar o ambiente urbano diversificado quanto às espécies empregadas, mais homogêneo e envolvente com a paisagem circundante. Em geral, as cidades, com ênfase ao Rio Grande do Sul, não se preocuparam, ao implantar suas arborizações, em criar uma fisionomia própria ao local, baseada em características regionais e culturais, pois a imagem da cidade não se traduz apenas nas vias, prédios e serviços, entre outros, ela se diferencia por todo o repertório de sua memória.

A recuperação ambiental e paisagística, a restauração de patrimônio cultural e de centros históricos, bem como a gestão de áreas verde visa à melhoria da qualidade de vida, considerando propostas mais participativas desde o poder público ao privado, com o enfoque na preservação dos espaços públicos e ambiências urbanas para a proteção do meio ambiente natural e ecossistemas ameaçados, refletindo a responsabilidade social e a busca da sustentabilidade (KATO, 1993; SIMÕES JÚNIOR, 1994; DOURADO, 1997).

A diversidade de espécies vegetais recomendadas para o plantio deve ser selecionada, de forma a permitir mais cor, visibilidade, conforto térmico, alimento para a fauna e proteção, permitindo ao usuário desfrutar de um ambiente integrado a paisagem nativa, a conservação e preservação da vegetação, bem como comprometê-lo da responsabilidade social que tem em relação ao ambiente. Segundo Hardt (1994):

O monitoramento da qualidade ambiental urbana deverá ter como fim precípuo à manutenção e ou melhoria das condições do ambiente urbano. $\mathrm{O}$ objetivo geral deve ser o de estabelecer um sistema multidimensional, integrado e dinâmico, de coleta, tratamento, arquivo, manutenção e operação de um conjunto de indicadores ambientais, devidamente parametrizados, que permitam avaliar, sistematicamente, a qualidade de vida que a cidade oferece a seus moradores. Devem ser incluídas no planejamento ações de conservação e ou minimização de danos ambientais diagnosticados pelo sistema, o qual deverá fornecer os subsídios necessários para a recuperação do meio, além de avaliar a eficácia das mesmas.

A amplitude da arborização urbana na questão ambiental ultrapassa as fronteiras das administrações públicas e privadas para situar-se também no seio da comunidade e na esfera da cidadania. $O$ estabelecimento de uma política de gestão sobre essas áreas de uso 
público reflete a preocupação com a qualidade do ambiente urbano onde se busca a utilização dos benefícios ecológicos, econômicos e sociais que a vegetação pode proporcionar na qualidade de vida dos usuários.

As pesquisas na arquitetura apresentam estratégias voltadas à sustentabilidade por meio do respeito aos recursos naturais, usando conceitos como permacultura, aproveitamento de energias renováveis, utilização de materiais e técnicas construtivas locais, gestão de resíduos, aproveitamento da água e da vegetação, começam a fazer parte dos projetos de arquitetos, engenheiros e profissionais envolvidos com 0 ambiente construído.

Isso porque, as cidades encantam por sua variedade, eventos, possibilidades de escolha e uma intensa estimulação que muitos indivíduos consideram um background (cenário) desejável para suas vidas. Elas proporcionam opções que nenhum outro arranjo social permite.

Por outro lado, a qualidade de vida nos centros urbanos tem sido cada vez mais questionada. Problemas como habitação, trânsito e transporte, segurança, lazer, urbanismo, preservação ambiental entre outros, têm deteriorado a qualidade de vida da população dos centros urbanos.

Admitindo-se que as cidades são indispensáveis nas sociedades complexas pode-se perguntar:

$\Rightarrow \quad$ Como se pode ajudar a avaliar a funcionalidade, adequação e preservação de ambientes urbanos, desde seu planejamento até sua ocupação?

$\Rightarrow \quad$ Como atuar sobre os ambientes urbanos e garantir a qualidade de vida?

$\Rightarrow$ Como as características ambientais das cidades têm influenciado no comportamento das pessoas no trânsito, no lazer, nas relações de vizinhança?

$\Rightarrow \quad$ Como se caracterizam e qual o uso dos espaços públicos existentes nos centros urbanos? A utilização destes espaços tem favorecido a circulação, o transporte, segurança?

$\Rightarrow \quad$ A opinião dos usuários tem sido considerada no planejamento dos ambientes das cidades? Até que ponto ela é importante?

$\Rightarrow \quad$ Por que desenvolver programas de educação ambiental, segurança e lazer com a participação da comunidade urbana?

Essas são apenas algumas das questões que permeiam o trabalho num ambiente urbano. Do ponto de vista comportamental é necessário cada vez mais à existência de espaços públicos para servir aos habitantes da cidade. Gehl (1989 apud DEL RIO 1990) sugere que a necessidade de vida pública nas cidades aumenta a cada dia, não só com a evolução política do Homem, mas com o perfil da vida moderna, com períodos cada vez 
menores e mais flexíveis de trabalho, famílias menores, aumento da expectativa de vida e aposentadorias mais precoces.

\begin{abstract}
Não se está falando somente do comportamento do usuário diante dos espaços de 'clausura' ou 'tortura' em relação às atividades em exercício. Refere-se também e principalmente aos 'gestos' de usuário no espaço, desde aqueles mais largos das 'manifestações de rua' até os mais comuns, da 'presa de quem vai para o trabalho, da tranqüilidade de quem usufrui um momento de folga, da disponibilidade de quem aguarda o transporte, da descontração de quem conversa em grupo nos passeios, da determinação ou indecisão de quem faz compras, da contemplatividade dos idosos ou da imprevisibilidade das crianças'. Qualquer modelo de classificação de atividades poderá ser útil na reflexão sobre a flexibilidade de projetos de espaços de uso coletivo e público em relação à multiplicidade de atividades no meio urbano. Esses comportamentos podem estar ligados a elementos tanto naturais (arborização, sombras, elevações, vistas significativas) como edificados (esquinas, passeios, escadarias), ou ainda a tipos de comércio, serviços e transportes, sempre presentes no cotidiano da vida coletiva no uso diurno e noturno do espaço urbano, cujo registro e mapeamento será o primeiro passo para a valorização de possíveis peculiaridades locais (RODRIGUES, 1986).
\end{abstract}

Mello e Cañelas (2000) descrevem praças como parcela do território urbano configurando um espaço público. Visto que para o urbanismo, a praça se caracteriza pelo contraste com a malha urbana que a cerca, é um vazio no meio de cheios, quebra a continuidade dos quarteirões edificados, introduz um elemento de surpresa e descontração.

Com isso, este trabalho tem como objeto de análise, a Praça Ernesto Tochetto, em Passo Fundo/RS em relação a importância na arborização e o resgate histórico deste espaço público multifuncional no contexto urbano.

\title{
MATERIAIS E MÉTODOS
}

O trabalho iniciou com o reconhecimento da situação da Praça Ernesto Tochetto, em Passo Fundo, RS. Na análise física foram verificadas as visuais internas e externas à praça em todos os quadrantes de forma a identificar a estrutura arbórea desta área, e a sua importância no contexto urbano local. Posteriormente foi feito em detalhamento da área com identificação e classificação da vegetação existente (MILANO, 1987, LORENZI, 1992; RODERJAN \& BARDDAL, 1998).

Com a análise histórica do local buscou-se fundamentar sua origem e importância no contexto histórico da cidade. Para isso aplicou-se um questionário aos freqüentadores da praça, em uma amostragem de 200 usuários com faixa etária de 15 a 70 anos, por um período de seis meses, a fim de verificar o que pensam a respeito da preservação histórica 
e o que sabem sobre a importância da praça na arborização. Foram elaboradas dez questões, entre elas: qual o nome da praça, local e equipamentos mais utilizados, turno que mais freqüenta a praça, distância da residência à praça em quarteirões, principais motivos que o levam a freqüentar a praça, iluminação e passeios com manutenção, presença de espécies arbóreas para sombra e flores, há um visual agradável e identificação das espécies arbóreas.

A partir da análise física e das respostas obtidas no questionário ${ }^{3}$ foram diagnosticados os usos, potencialidades e deficiências do local, além de seu valor perante a comunidade em geral e seus usuários.

\section{RESULTADOS E DISCUSSÕES}

O crescente interesse por espaços de recreação e convívio para a melhoria das condições de ambiência urbana foi se consolidando com a criação de parques e praças municipais ou clubes e áreas de lazer privadas.

As praças surgiram primeiramente com a função de mercado, passando posteriormente a cumprir outras funções, como a cívica, a recreativa, a contemplativa e a ecológica. No entanto nunca perderam a característica de serem locais extremamente sociais. Sua inserção nas cidades confere características próprias de cada local o que reflete diferentes traçados e composições vegetais. A maior ou menor integração destes espaços com a malha urbana e a sua apropriação pela comunidade é reflexo do grau de visibilidade imposto pelo entorno diretamente à praça e vice-versa, o qual é conseqüência direta das estruturas vegetais empregadas.

Por ser a praça um elemento que se caracteriza pelo contraste com a malha urbana que a cerca, é um vazio no meio de cheios, quebra a continuidade dos quarteirões edificados, introduz um elemento de surpresa e descontração, além de ser essa área verde urbana, que proporciona melhorias no ambiente impactado das cidades e benefícios para os habitantes das mesmas, por possui as seguintes funções:

$\Rightarrow \quad$ Função psicológica: ocorre, quando as pessoas em contato com os elementos naturais dessas áreas relaxam, usufruindo momentos de lazer e recreação.

$\Rightarrow \quad$ Função ecológica: deve-se ao fato da presença da vegetação, do solo não impermeabilizado e de uma fauna mais diversificada nestas áreas, promovendo melhorias no clima da cidade e na qualidade do ar, água e solo.

\footnotetext{
${ }^{3}$ Os dados foram tabelados no Excel e analisados no programa SPSS (Statiscal Package Social Science).
} 
$\Rightarrow \quad$ Função social: está intimamente ligada com a possibilidade de lazer que estas áreas oferecem à população.

$\Rightarrow \quad$ Função estética: diz respeito à diversificação da paisagem construída e o embelezamento da cidade.

$\Rightarrow \quad$ Função educativa: está relacionada com a possibilidade imensa que essas áreas oferecem como ambiente para o desenvolvimento de atividades extra classe e de programas de educação ambiental.

Devido à complexidade da relação ambiente - comportamento muitas vezes faz-se necessário um diagnóstico sobre a situação existente. Visto que, nas cidades onde a arborização urbana já está implantada, além do acompanhamento técnico, necessita-se de uma reformulação planejada e amplamente discutida na comunidade. Além disso, devem-se levar em consideração os aspectos culturais e históricos da população local, suas necessidades, anseios e conhecimento da situação original, devendo ser destacado a seleção e características das espécies a serem implantadas (CUNHA et al, 2003).

Deste modo, a Praça Tochetto, originada em meados de 1963, conhecida primeiramente pelo nome de Praça da República, tipicamente para uso de lazer e contemplação, localizada em uma área completamente residencial, acabou modificando suas características originais em função do crescimento e desenvolvimento urbano. Adquiriu este nome, "Praça Tochetto", em homenagem ao emérito educador Ernesto Tochetto falecido em 07 de abril de 1956, com sua imagem preservada até hoje na representação da sua sala de aula, com as classes sobre o canteiro e ao fundo o quadro negro, único recurso de sua época, com a esfinge do professor sobre o pedestal à frente lembrando a tradicional posição da autoridade do mesmo (Figura 01). 


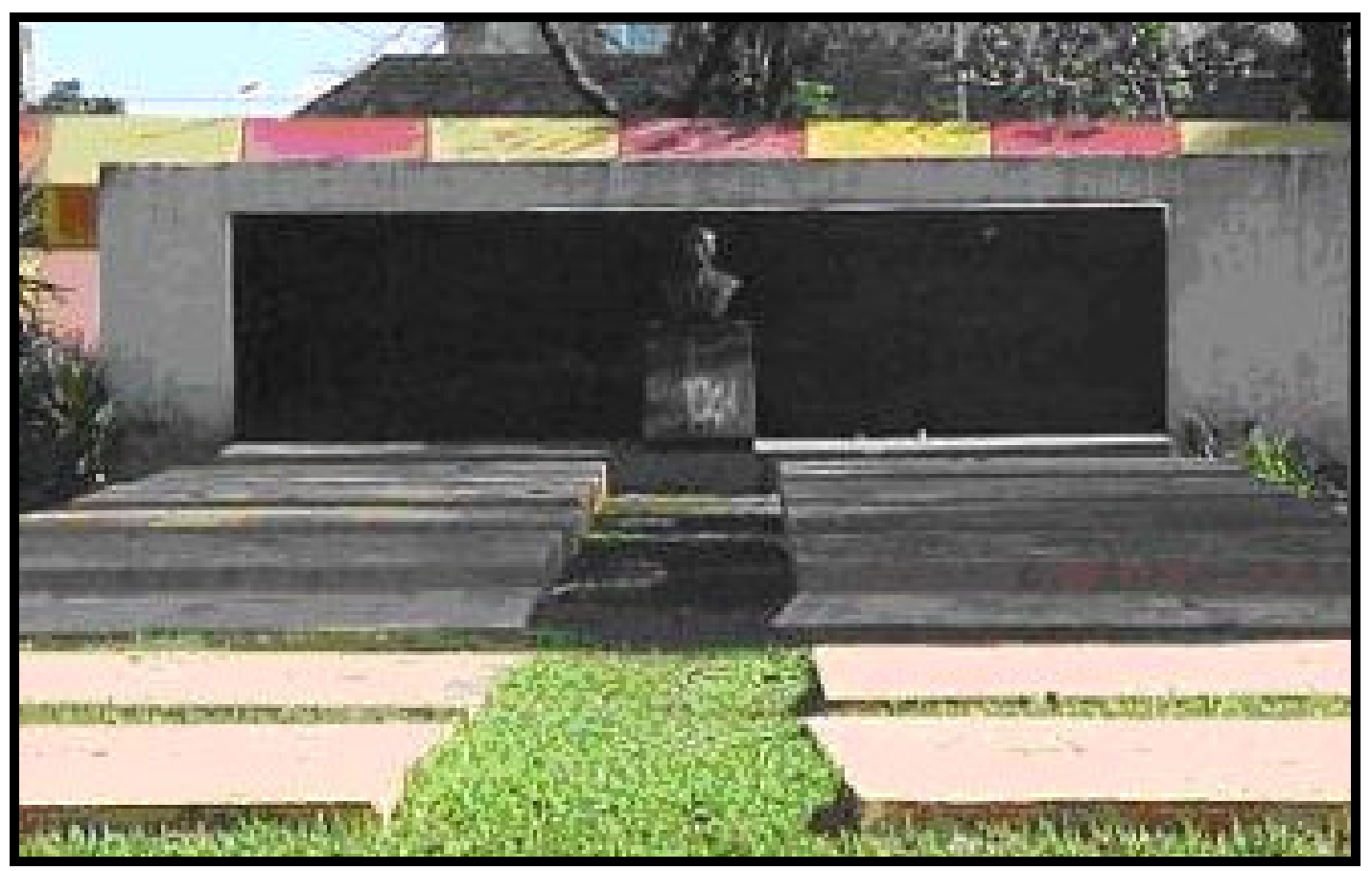

Figura 01. As classes são representadas sobre o canteiro da praça e ao fundo está o quadro negro com a esfinge do professor Tochetto sobre o pedestal na frente do quadro, lembrando a posição tradicional da autoridade do professor.

Fonte: Prefeitura Municipal de Passo Fundo, 2003.

Mas nem por isso ela é reconhecida pelos habitantes da cidade. Quando questionados sobre o nome, $42 \%$ dos usuários não sabiam o real nome da Praça. Estes dados, principalmente entre os mais jovens, revelaram o desconhecimento da identidade sócio-cultural que estes espaços traduzem, alheia ao registro de sua própria história, fruto da soma do tempo e de sua evolução. Nela ainda estão assentados três monumentos de características históricas (Quadro 01), visíveis ao se transitar nos passeios, sendo eles marcos na memória sócio política e cultural do município.

Ferrara (2000) justifica que a compreensão de um cenário urbano precisa relacionar a imagem física com a imagem produzida pelo imaginário vinculando seus significados para interpretar as dimensões de uso cotidiano, criando a percepção da verdadeira imagem.

Lynch (1999) ainda acrescenta que todo ser possui a capacidade de estruturar e identificar o meio ambiente em que vive. Para tal prática utiliza-se dos sentidos e desenvolve técnicas de orientação baseadas no meio ambiente. Tendo uma imagem clara e positiva deste meio desloca-se com segurança e rapidez. 
Quadro 01. Características históricas dos monumentos da Praça Ernesto Tochetto.

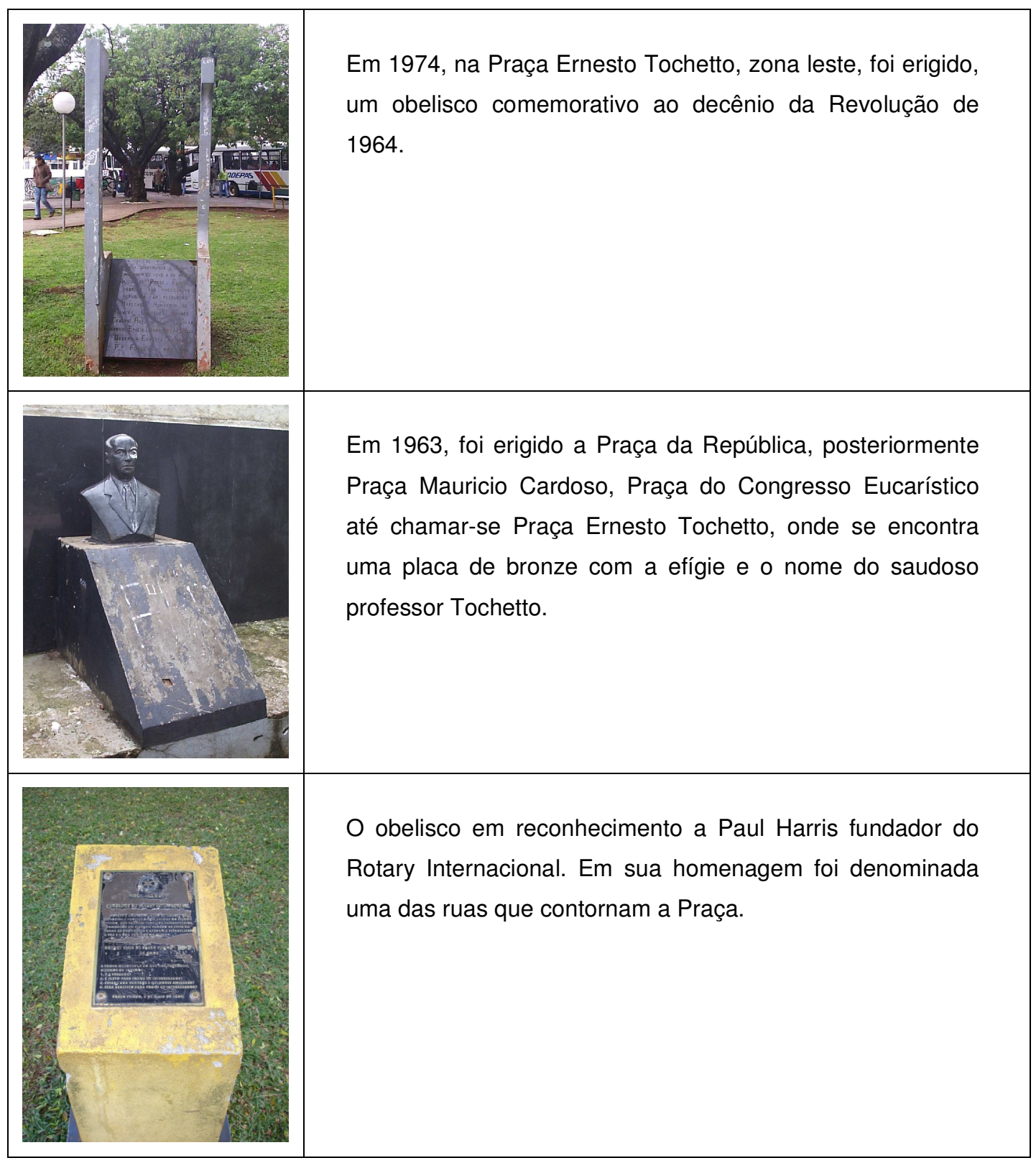

Localizada entre a Avenida Brasil, as ruas Benjamin Constant, Fagundes dos Reis e Paul Harris (Figura 02), possui uma posição privilegiada, inserida entre duas ruas que fazem ligação, entre centro e bairros, tem um entorno diversificado que inclue uma escola, estabelecimentos comerciais, comércio informal e pela área residencial. 


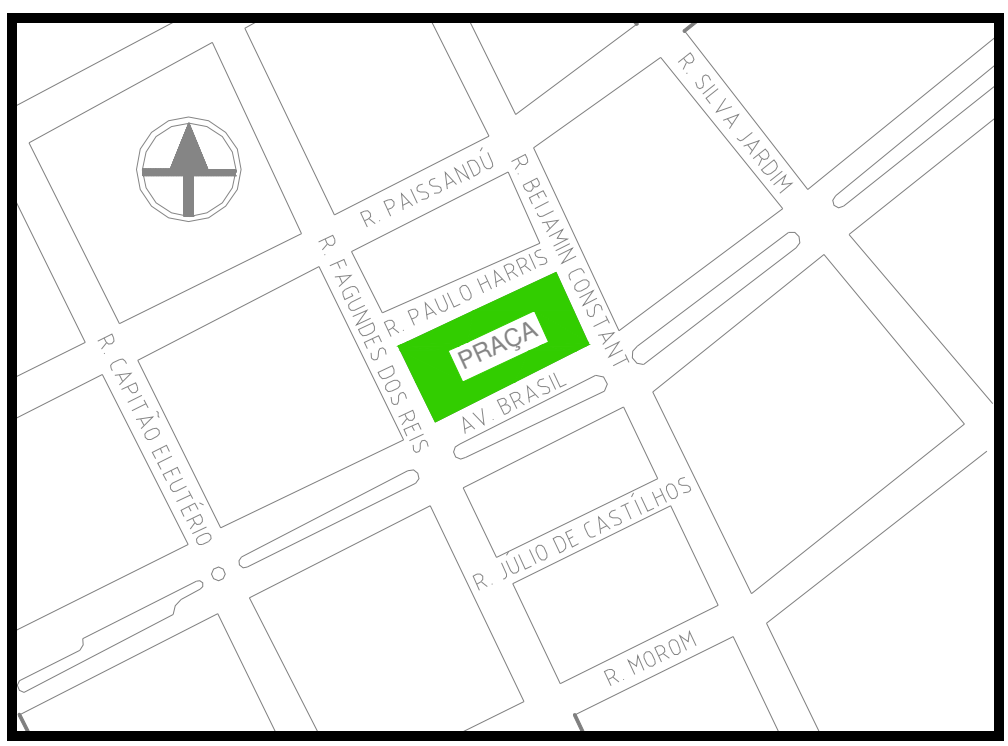

Figura 02. Área de intervenção.

Fonte: Autoras, 2004.

O estudo realizado na Praça Ernesto Tochetto, demonstrou que a mesma perdeu suas características originais, deixando de ser um espaço estritamente de lazer e recreação como apoio à área residencial e a escola, para constituir-se em um espaço público multifuncional de grande importância no contexto urbano local, pois hoje é um ponto de referência e valorização dos imóveis próximos a ela. Abriga vários usos, de passagem ou como um elo entre os bairros e o centro da cidade, comércio informal (Figura 03), além da sua função primordial de convívio, lazer e recreação (Figura 04 e 05).

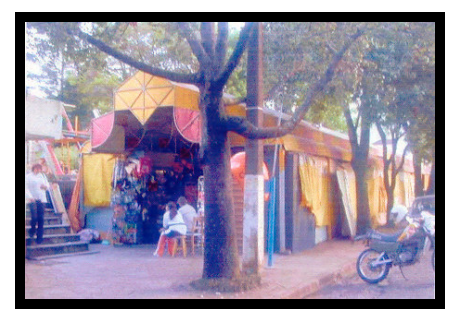

Figura 03. Praça Tochetto, comércio informal. Fonte: Autoras, 2004.

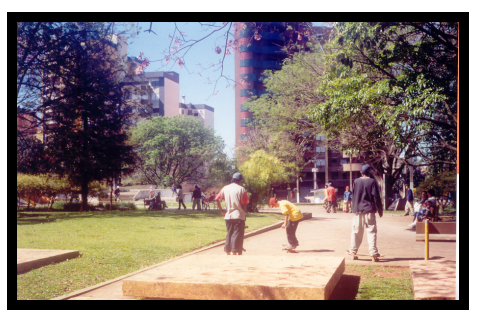

Figura 04. Praça Tochetto, lazer e recreação. Fonte: Autoras, 2004.

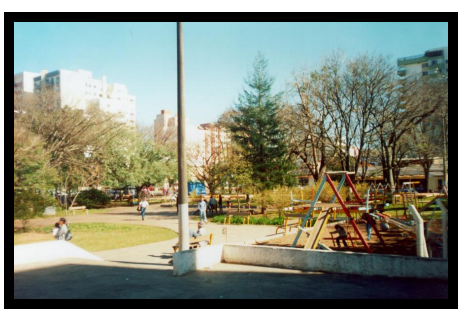

Figura 05. Foto da Praça Ernesto Tochetto. Fonte: Corazza, 2003.

O traçado formal da praça é marcado por dois eixos diagonais que distinguem setores onde a vegetação complementa o mobiliário (Figura 06). A área central e sudeste são mais permeáveis devido a pouca vegetação e pela presença de uma quadra poliesportiva. Nos demais quadrantes a posição do observador/usuário tem visuais comprometidos do entorno pela presença de várias tipologias de estruturas globosas (Ligustrum japonicum), piramidal (Brachichitum populneum) e umbeliformes (Tipuana tipu, 
Ficus sp., Enterolobium contortisiliquum e Tabebuia sp.). Outras espécies são encontradas no interior da praça que dificultam a leitura dos espaços internos e externos como a (Phytolaca dioica e Tabebuia sp.) além da Sequóia e Manduirana (Senna macranthera).

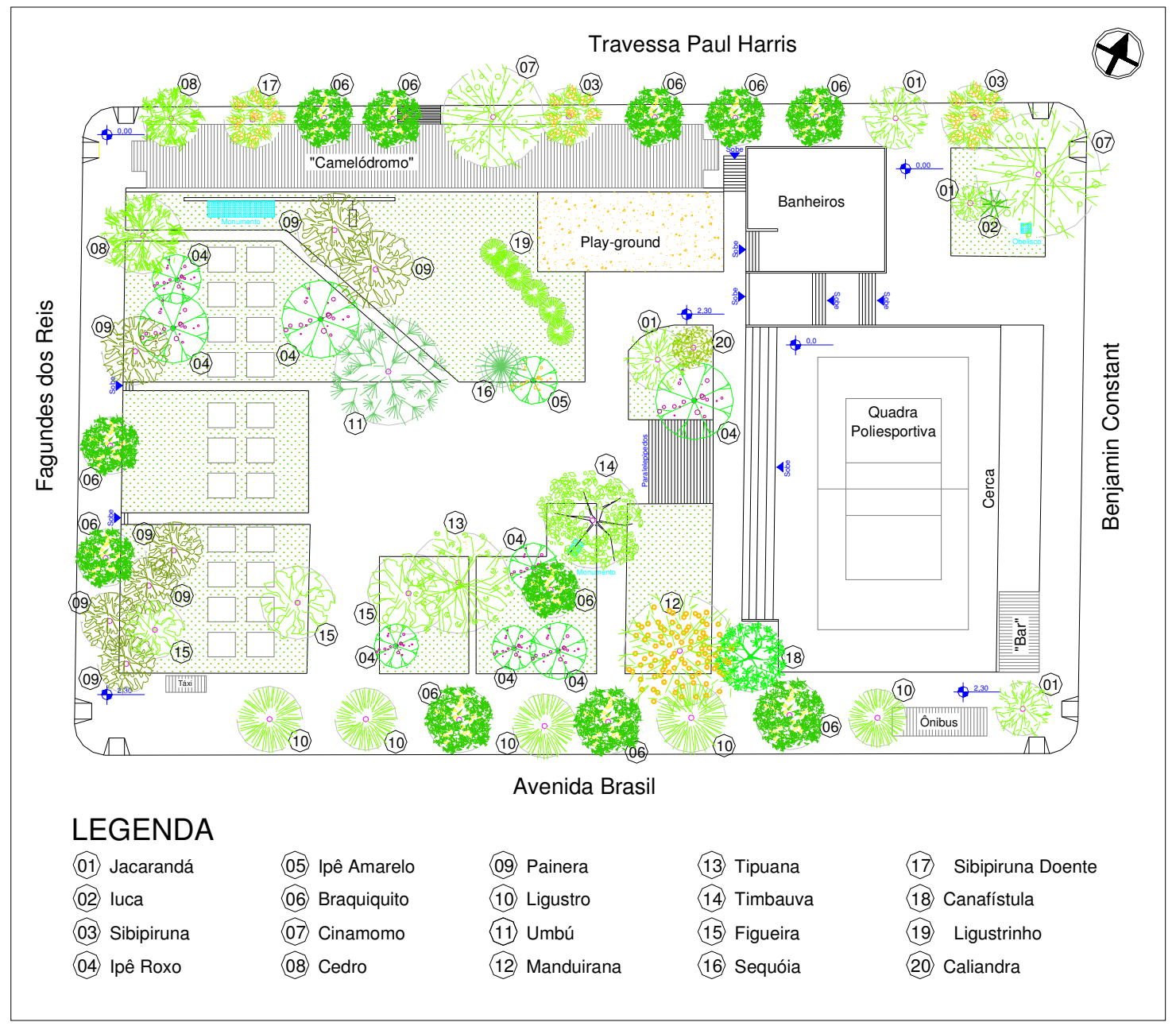

Figura 06. Planta baixa da Praça Ernesto Tochetto, Passo Fundo, RS.

Fonte: Autoras, 2004.

A análise física, complementada pela análise dos questionários verifica o anseio por melhoramento dos bancos, monumentos, aumento de árvores com flores, iluminação e passeios, identificando a falta de cores (Quadro 2). A maioria dos entrevistados tem entre 15 e 30 anos, especialmente em função da proximidade com a escola e a presença de quadra esportiva, utilizando mais no período da tarde o espaço de lazer. Observa-se que a faixa etária mais jovem considera suficiente a quantidade de sombra e utilizam como via de passagem preferencialmente. Os usuários com idade entre 46 e 70 anos percebem a praça com visual agradável, porém indicam a necessidade de mais bancos além de manutenção, 
assim como, sugerem maior número de espécies arbóreas com flores e reconhecem algumas pelo nome vulgar.

Quadro 2. Considerações em percentagem sobre as principais questões de uso, potencialidades e deficiências da praça Ernesto Tochetto, Passo Fundo, 2004.

\begin{tabular}{|l|c|c|c|}
\hline \multirow{2}{*}{ Principais elementos do diagnóstico } & \multicolumn{3}{|c|}{ Faixa etária } \\
\cline { 2 - 4 } & $15-30$ & $31-45$ & $46-70$ \\
\cline { 2 - 4 } & \multicolumn{3}{|c|}{$\%$} \\
\hline Idade dos entrevistados & 38 & 32 & 30 \\
\hline Não sabem o nome da praça & 42 & 35 & 23 \\
\hline Utilizam como via de passagem & 52 & 28 & 20 \\
\hline Utilizam para recreação e lazer & 33 & 31 & 36 \\
\hline Turno que mais freqüentam a praça - tarde & 40 & 15 & 45 \\
\hline Quantidade de bancos insuficiente necessitando manutenção & 26 & 36 & 38 \\
\hline Iluminação suficiente e passeios conservados & 32 & 33 & 35 \\
\hline Quantidade de sombra suficiente & 45 & 30 & 25 \\
\hline Falta de espécies arbóreas com flores & 31 & 30 & 39 \\
\hline Visual da praça agradável & 29 & 35 & 36 \\
\hline
\end{tabular}

Como se verifica em planta, a praça não possui vegetação adensada, sendo portanto, um local que proporciona espaços ao sol e na sombra, não causando, portanto variações tão significativas na temperatura (Quadro 03).

Quadro 03. Relação estação medida com dados meteorológicos - Praça Ernesto Tochetto.

\begin{tabular}{|l|l|c|c|c|c|c|c|}
\hline \multicolumn{2}{|c|}{ ESTAÇ̃̃O } & \multicolumn{2}{c|}{ DADOS METEOROLÓGICOS } & \multicolumn{3}{c|}{ DADOS MEDIDOS } \\
\hline & & $\begin{array}{c}\text { Temp. máx. } \\
{ }^{\circ} \mathrm{C}\end{array}$ & $\begin{array}{c}\text { Umidade } \\
\%\end{array}$ & $\begin{array}{c}\text { Vel. } \\
\text { Média } \\
\text { Vento }\end{array}$ & $\begin{array}{c}\text { Temperatura } \\
\text { de bulbo seco } \\
\left({ }^{\circ} \mathrm{C}\right)\end{array}$ & $\begin{array}{c}\text { Umidade } \\
\text { relativa } \\
(\%)\end{array}$ & $\begin{array}{c}\text { Velocidade } \\
\text { do vento - } \\
(\mathrm{m} / \mathrm{s})\end{array}$ \\
\hline 1 & sol & $14,5^{\circ} \mathrm{C}$ & $63 \%$ & $7,7 \mathrm{~m} / \mathrm{s}$ & 16,6 & 42,3 & 2,5 \\
\hline 2 & sombra & $14,5^{\circ} \mathrm{C}$ & $63 \%$ & $7,7 \mathrm{~m} / \mathrm{s}$ & 17,2 & 40,0 & 0,0 \\
\hline
\end{tabular}
Fonte: CORAZZA, 2003.

Quanto à vegetação arbórea verificou-se uma grande diversidade de plantas na Praça, tendo sido catalogadas 15 espécies arbóreas num total de 52 exemplares (Figura 07). A paisagem rica e diversificada de um espaço destinado à grande circulação de pessoas como se caracteriza a Praça Ernesto Tochetto, é garantia de um ambiente onde há benefícios ecológicos, sociais e econômicos. No entanto, grande parte da população nem 
sempre reconhece estes benefícios e muito menos os nomes das árvores utilizadas na arborização (RODERJAN e BARDDAL, 1998).

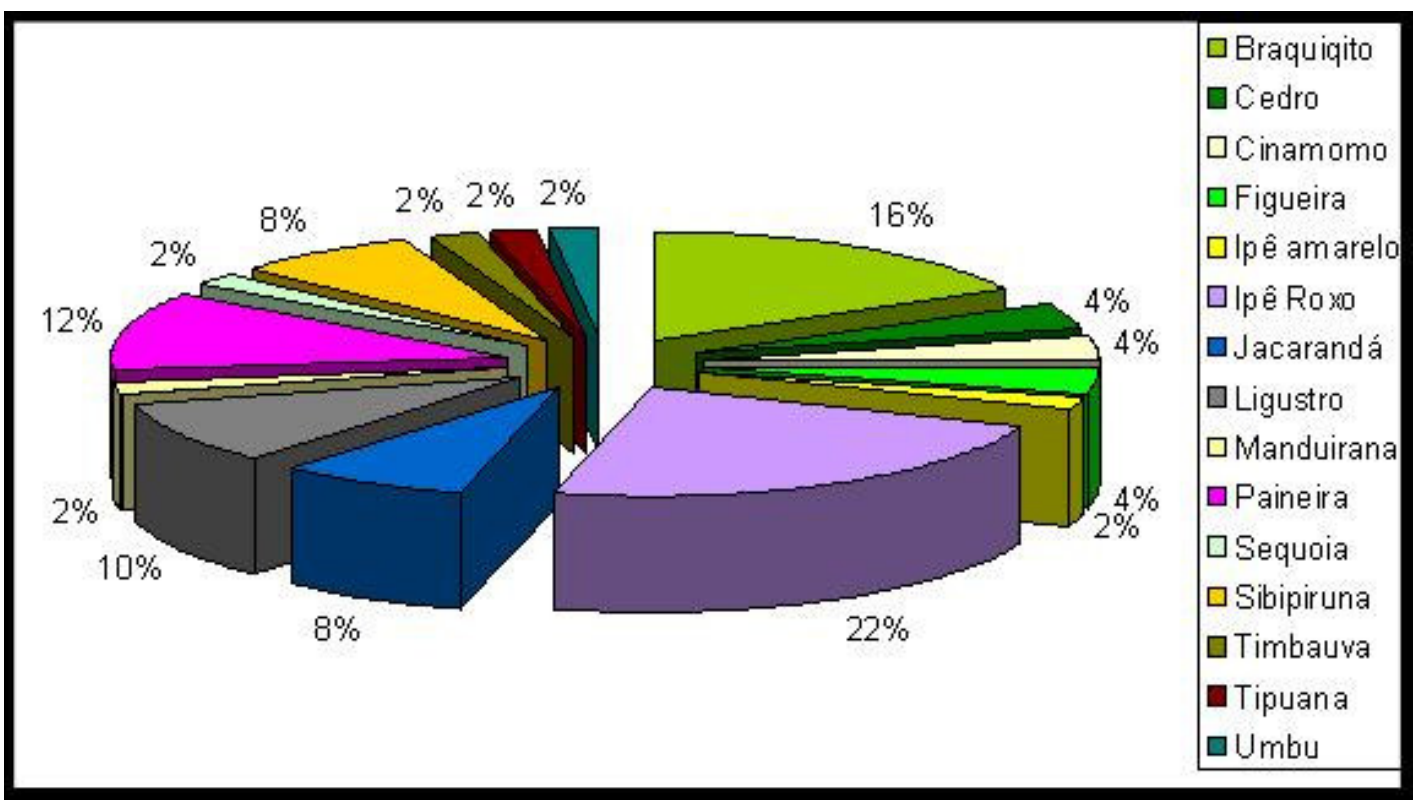

Figura 07. Espécies arbóreas existentes na Praça Ernesto Tochetto, Passo Fundo, RS, 2003.

Fonte: Autoras, 2003.

Há um predomínio de espécies decíduas, mas as espécies perenes, mesmo com menor representação botânica predominam quanto à densidade da folhagem. Já a presença de Ligustrum japonicum e Brachichitum populneum na área externa, junto ao passeio se traduz no fechamento e sombreamento do local. A presença do Ligustrum japonicum pela tonalidade de suas folhas torna o ambiente escuro diminuindo a expressão cromática. Santos \& Melo (2003) apontaram nos resultados da pesquisa a necessidade de redução dos Ligustrum japonicum na cidade de Passo Fundo em função de riscos à saúde pública.

Outro fator importante do ponto de vista estético é o florescimento, expresso pela Chorisia speciosa e Tabebuia sp. (cor rosa), Jacaranda mimosaefolia (cor azul violáceo), Senna macranthera e Caesalpinia pluviosa (cor amarela) e Phytolaca dioica (cor branca). Embora ocorram flores nos períodos de julho a abril, há um predomínio em setembro de cor rosa e em novembro e janeiro de cor amarela, porém os exemplares presentes das referidas espécies predominam a cor rosa e azul violáceo. Outra espécie, como a Tipuana tipu, embora com flores amarelas, não apresenta florada tão expressiva em razão do pequeno tamanho das flores (Figura 08).

A área central (nordeste) é marcada pela monumentalidade do Umbu (Figura 09), vegetação que além de seu aspecto de floração tem suas significativas raízes tabulares, portanto só pode ser utilizada em praças e não na arborização das vias. 




Figura 08. Florescimento da Praça Ernesto Tochetto, Passo Fundo, RS.

Fonte: Autoras, 2004.
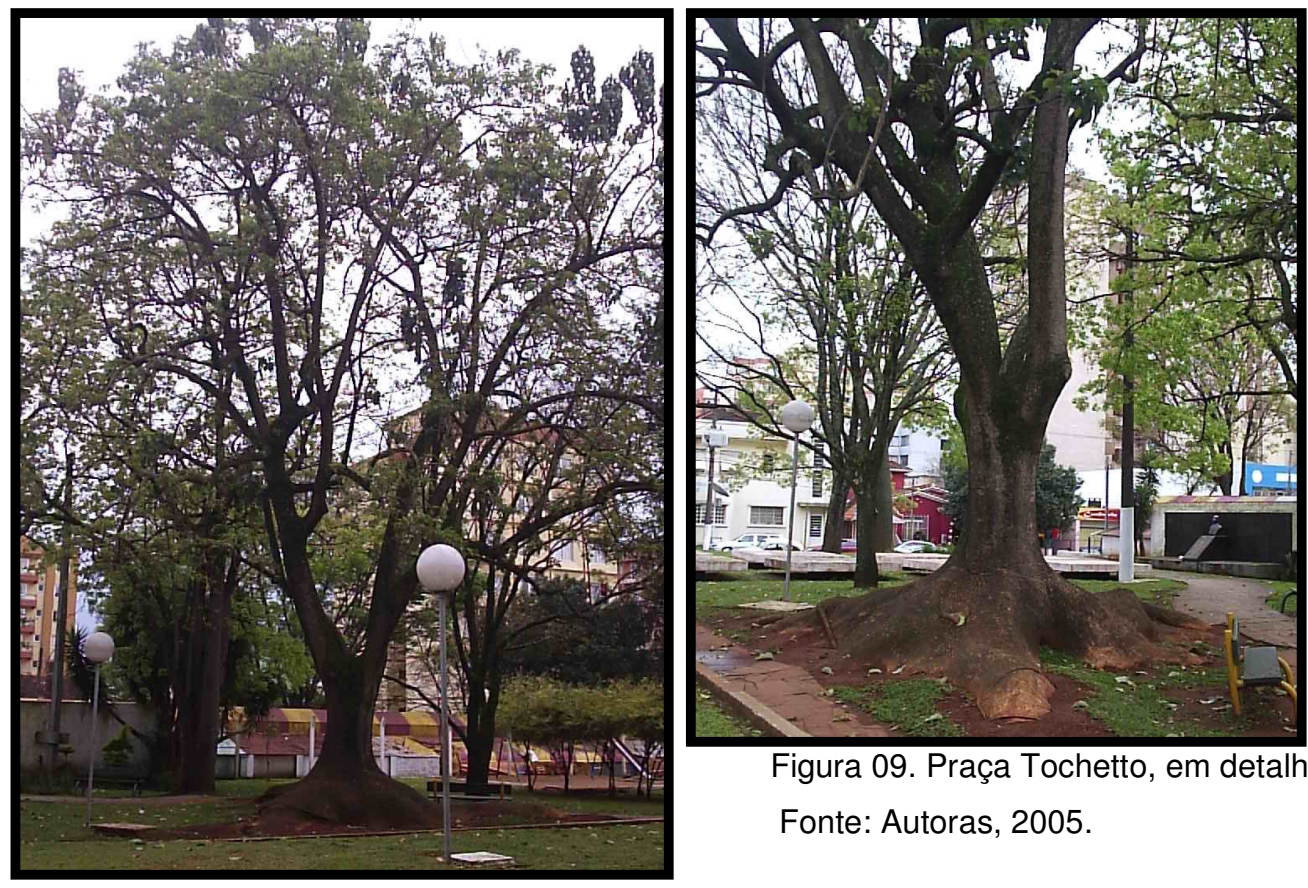

Figura 09. Praça Tochetto, em detalhe Umbu.

Fonte: Autoras, 2005. 
Destaca-se também a Sequóia (Figura 10), uma planta exótica que vem da América do Norte e se adaptou ao local, convivendo juntamente com a predominância de vegetação nativa existente, com forma e copa piramidal, tornando-se um ponto de grande visitação local.

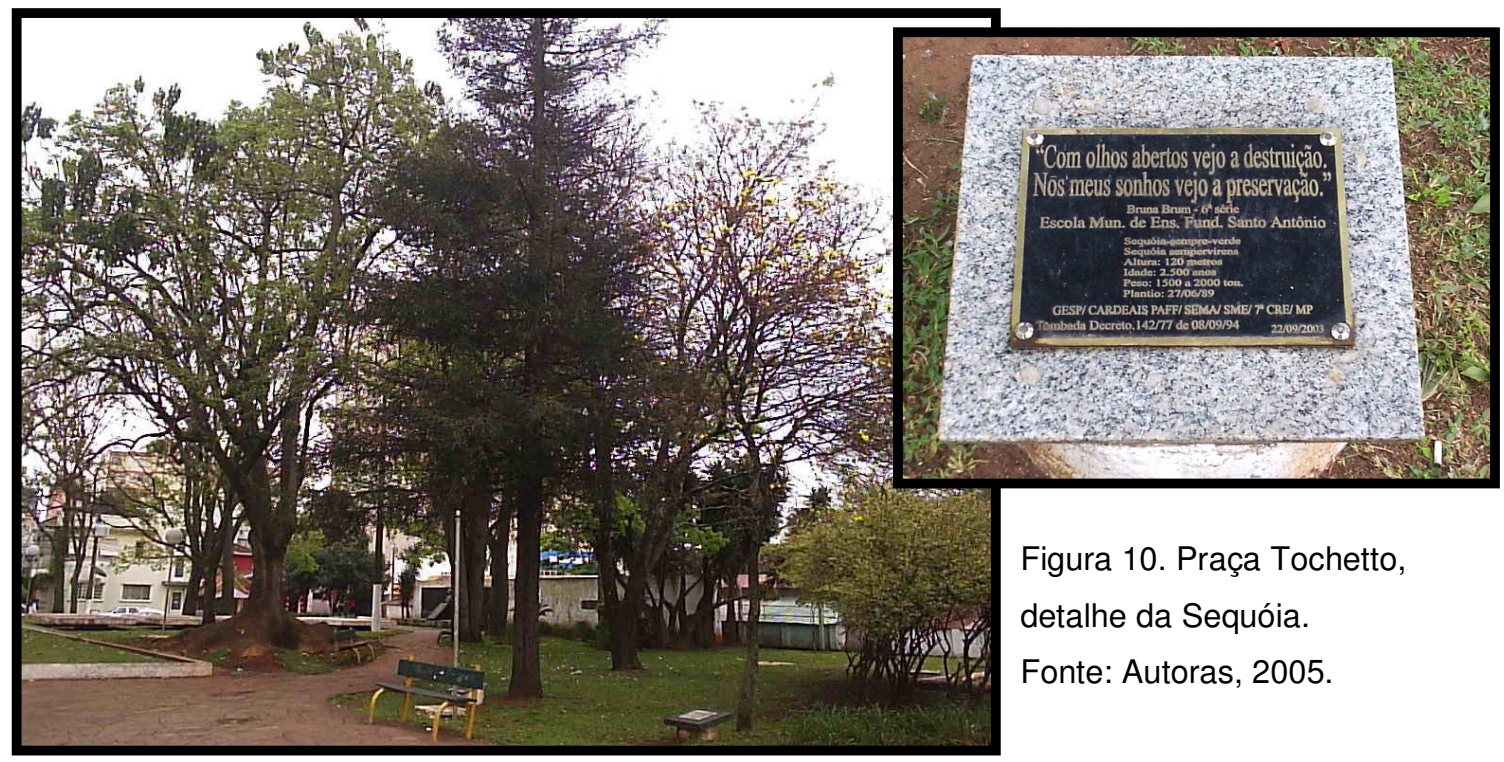

$\mathrm{Na}$ análise da Praça Ernesto Tochetto percebe-se a preocupação com a ambiência, qualidade de vida da população e resgate histórico, cultural e social tendo na vegetação um grande aliado, pela utilização das espécies ornamentais com intuito paisagístico de composição cênica ou de destaque dos ambientes, que com o passar dos anos agregou diferentes aspectos funcionais e múltiplos objetivos, concordando com ROCHA et al., 1995; ANGELIS NETO e ANGELIS, 1999; MARENZI, 1999.

Quando visualizada do entorno, observa-se que a praça possui exemplares globosos de folhagem escura (Ligustrum japonicum) e exemplares piramidais (Brachichitum populneum), com espaçamentos desordenados, como na Avenida Brasil (Figura 11), onde ocorre maior concentração destes exemplares. Além das espécies acima citadas, outras existentes proporcionam graus de fechamento distintos como o que ocorre na Rua Paul Harris onde há presença das espécies cedro (Cedrela fissilis), Braquiquito (Brachichitum populneum) e Sibipiruna (Caesalpinia pluviosa), aliado ao camelodromo. Já na Rua Fagundes dos Reis encontram-se exemplares volumosos de paineira (Chorisia speciosa). 


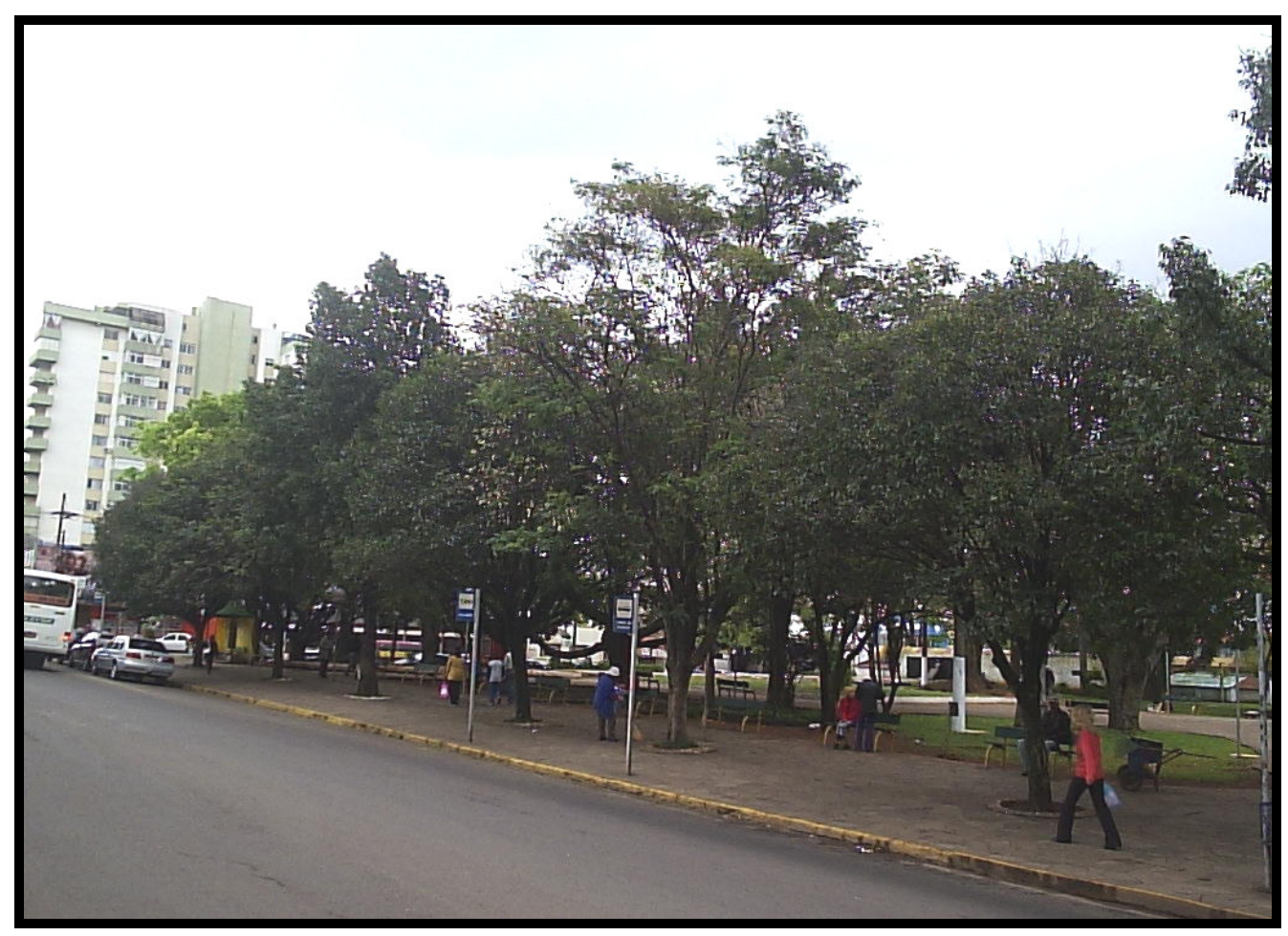

Figura 11. Visual da Praça Tochetto, vista da Avenida Brasil.

Fonte: Autoras, 2005.

A Praça é um espaço público multifuncional de grande importância no contexto urbano local, pois convida ao convívio social, a prática de esportes e atividades de lazer ao ar livre. É palco de manifestações coletivas e que muitas vezes abriga atividades provisórias como feiras, espetáculos musicais, festas folclóricas, entre outras. Por evocar o ambiente natural, esta requer tratamentos paisagísticos especial, propiciando ainda mais um espaço agradável para contemplação, leitura, conversas com os amigos ou simplesmente o descanso.

O efeito do ambiente sobre o comportamento humano não é analisado de forma isolada ou unidirecional, considera-se o contexto em que ele ocorre. Enfatiza-se a relação recíproca, ou seja, tanto o ambiente influencia o comportamento, quanto é influenciado por ele. "Os parques e a natureza são importantes para a saúde das pessoas de diferentes formas considerando-se a redução do stress, alteração hormonal e no sistema imunológico, como processo de cura" (GRAHN, 1994). Assim, as áreas verdes são fundamentais pelos benefícios ecológicos, econômicos e sociais que a vegetação pode proporcionar na qualidade de vida dos usuários. 


\section{CONCLUSÕES}

Se preservados, os espaços arquitetônicos e urbanísticos proporcionam a convivência dos valores históricos e culturais de uma sociedade. $O$ estudo conclui que a Praça Ernesto Tochetto resgata a memória de seus antepassados com suas características originais, mas esbarra no desinteresse dos usuários quanto a sua história. Assim, cabe a sociedade passofundense encontrar as formas de manter, preservar e até reconstruir sua memória, sob pena de negar esse direito às gerações futuras. A Praça é um espaço público multifuncional de grande importância no contexto urbano local, pois convida ao convívio social, a prática de esportes e atividades de lazer ao ar livre. É palco de manifestações coletivas e que muitas vezes abriga atividades provisórias.

A praça apresenta grande diversidade de espécies arbóreas sendo um local de preservação da vegetação nativa e referência pela presença de um exemplar de Sequóia.

O estabelecimento de uma política de gestão sobre áreas verdes de uso público reflete a preocupação com a qualidade do ambiente, onde a preservação e a interação dos vários segmentos pode solucionar alguns problemas ambientais. Não importa qual a esfera, está acima do individualismo e das ações isoladas, em que os caminhos para minimizar as situações conflitantes já existentes perpassam pelo trabalho coletivo, conhecimento científico, revisão de conceitos e mudanças de mentalidade. Os hábitos de uma sociedade só se transformam através de uma mudança de princípios e valores.

\section{REFERÊNCIAS BIBLIOGRÁFICAS}

ANGELIS NETO, G de e ANGELIS, B.L.D. de Plantas ornamentais: do paisagismo a outras aplicações. Rev. Bras. Hortc. Ornam. , Campinas, v.5, n.1, p.12-19, 1999.

CORAZZA, Jaqueline. Morfologia urbana e microclima. Passo Fundo, 2003. Monografia (Especialização), FEAR, Universidade de Passo Fundo, 2003.

CUNHA, E.G. da; FRANDOLOSO, M.A.L; MASCARÓ, J.J.(Org.). Elementos de arquitetura de climatização natural. Passo Fundo : UPF, 2003, 145p.

DIEHL, Astor Antônio. Memória Fotográfica de Passo Fundo. Passo Fundo: UPF Editora, 1997.

DOURADO, Guilherme D (Org.). Visões de Paisagem. São Paulo: Associação Brasileira de Arquitetos Paisagistas, 1997. 
FERRARA, Lucrecia D’Alessio. Os significados urbanos. São Paulo: Edusp, 2000.

GRAHN, P. The importance of green urban áreas for people'swell-being. European Regional Planning n. 56, 1994, pp. 89-112.

HARDAT, L. P.A. Áreas verdes como meio de recuperação de áreas degradadas urbanas. In: SIMPÓSIO SUL-AMERICANO E SIMPÓSIO NACIONAL RECUPERAÇÃO DE ÁREAS DEGRADADAS, 1994, Curitiba. Anais... Curitiba: FUPEF, 1994. p.173-184.

KATO, Akinori. Plazas of Southern Europe. Tokio: Process Architecture, 1993.

LORENZI, H. Árvores brasileiras. Nova Odessa: Ed. Plantarum, 1992. 352p.

LYNCH, Kevin. A imagem da cidade. São Paulo: Martins Fontes, 1999.

MARENZI, Rosemeri Carvalho. A influência da Vegetação nas Preferências Paisagísticas no Município da Penha. In: CONGRESSO NACIONAL DE BOTÂNICA, 50, Blumenau/SC, 1999. Programa e Resumos. Blumenau: Soc. Bot. Br., 1999. Pág. 150.

MELLO,E.; CAÑELAS, K. Conceitos de paisagismo. In apostila de aula. Curso de Arquitetura e Urbanismo. Universidade de Passo Fundo. Passo Fundo,2000.

MILANO, M.S. O planejamento e o replanejamento da arborização de ruas. In: ENCONTRO NACIONAL DE ARBORIZAÇÃO URBANA,2, 1987, Maringá. Anais... Maringá: PMM,1987. p.01-08.

ROCHA, Emerson A. e AGRA, Maria de F. Cactaceae Medicinais da Paraíba, Brasil. In: CONGRESSO NACIONAL DE BOTÂNICA, 49, Salvador/BA, 1998. Resumos. Salvador: Soc. Bot. Br., 1998. p. 285

RODERJAN, C. V. \& BARDDAL, M. L. Arborização das Ruas de Curitiba - PR. Guia Prático para a Identificação das Espécies. Curitiba: FUPEF, 1998. 14p.

RODRIGUES, Ferdinando de Moura. Desenho urbano, cabeça, campo e prancheta. São Paulo: Projeto, 1986. 
SANTOS, N.Z. \& MELO, E.F.R.Q. Incidência de ligustro (Ligustrum japonicum Thumb) na arborização de vias públicas. In: CONGRESSO FLORESTAL ESTADUAL, 2003. Anais...Nova Prata: UFSM, 2003. Cd-rom

SIMÕES JÚNIOR, José Geraldo. Revitalização de centros urbanos. Polis, n. 19, 1994, $73 p$. 